\title{
Lignin-carbohydrate Complexes from Coconut (Cocos nucifera) Coir: Fractionation, Structural Elucidation, and Potential Applications
}

Qi Zhou, ,ab Zhiqiang Ou, ${ }^{\mathrm{a}, \mathrm{b}}$ Xin Rao, ${ }^{\mathrm{a}, \mathrm{b}}$ Yi Liu, ${ }^{\mathrm{c}}$ Chen Liang, ${ }^{\mathrm{c}}$ Liming Zhang, Chunqing Huo, ${ }^{a}$ and Xueyu $\mathrm{Du}^{\mathrm{a}, \mathrm{b}, *}$

Coconut coir, a major type of tropical lignocellulosic waste, has been restricted from higher-value applications due to its chemical complexity and inherent variability. To better disclose the chemical relationships between polysaccharides and lignin in coir and further exploit its high value-added bio-based materials, two lignin-carbohydrate complexes (LCCs) designated as glucan-lignin (GL) and xylan-lignin ( $\mathrm{XL}$ ) were successively isolated from coir via a simplified and quantitative fractionation method. The characterization of chemical composition, molecular weight distribution, and constituent substructures of the isolated LCC fractions were examined, and the lignin-carbohydrate (LC) chemical linkages were revealed as $y$-esters by a 2D heteronuclear singular quantum correlation (HSQC) NMR technique. Furthermore, XL was demonstrated as a more competitive candidate than GL for 2,2-diphenyl1-picryl-hydrazyl (DPPH) removal in comparison with 2,6-di-tert-butyl-4methylphenol (BHT, a commercial antioxidant), and was also featured as a more promising reinforcing agent for elevating the adsorption property of polyacrylamide-based hydrogels via the synergistic effect of physical and hydrogen bonding adsorptions.

Keywords: Coconut coir; Lignin-carbohydrate complex (LCC); Fractionation; Radical scavenging; Adsorption property

Contact information: a: Key Laboratory of Advanced Materials of Tropical Island Resources of Ministry of Education, School of Chemical Engineering and Technology, Hainan University, 570228 Haikou, China; b: Hainan Provincial Key Lab of Fine Chemistry, Hainan University, 570228 Haikou, China; c: College of Light Industry and Food Engineering, Guangxi University, 530004 Nanning, China;

* Corresponding author: duxueyu@ hainanu.edu.cn

\section{INTRODUCTION}

Biomass wastes, as an alternative to fossil resources, have been continuously highlighted as the most abundant, cost-effective, and sustainable raw materials for production of energy, platform chemicals, and bio-based materials (Menon and Rao 2012; Bian et al. 2019a; Cho et al. 2020). The rational utilization of biomass wastes not only plays a crucial role in environmental improvements but also elevates the inherent value of natural polymers stemming from the feedstocks. Irrespective of the species of lignocellulosic wastes, cellulose, lignin, and hemicellulose are commonly recognized as the three dominating components that possess huge application potentials after efficient isolation (Ragauskas et al. 2014; Grishkewich et al. 2017; Naidu et al. 2018; Bian et al. 2019b; Huang et al. 2019; Pang et al. 2019). 
Coconut is one of the popular tropical fruits and widely cultivated in at least 94 countries including the tropical areas of Asia, Oceania, Africa, and the Americas. According to Food and Agriculture Organization of the United Nations (FAO), the global cultivation area of coconut in 2014 was 12 million hectares with a total output of 60 million tons of coconut (whole fruit). Indonesia and the Philippines are the top two coconutproducing countries, and their coconut production in 2014 were up to 19.1 tons and 14.7 tons according to the statistics division of FAO (FAOSTAT) 2017 (Bourdeix and Prades 2018; Srivaro et al. 2020). In southern China, annually, a great deal of coconut husk waste is disposed into the environment, though some part of it is recycled and processed for the fabrication of low value-added products, e.g., activated carbon, mattresses, brushes, etc. The deep utilization strategy towards coconut residues is aimed for high value-added products; therefore, the practice is highly stimulated, and the pertained efforts have been dedicated. For instance, a novel and green approach consisting of organosolv pulping and low concentration treatment of sulfuric acid was developed for the preparation of cellulose nanowhiskers from white coconut coir (Nascimento et al. 2014). Property-reinforced biodegradable poly(vinyl alcohol) (PVA) composite films were prepared by addition of cellulose nanofibrils isolated from coconut coir (Wu et al. 2019).

However, a facile process has not been reported to isolate the specific type of components that achieve high yield and high purity at the same time. Any attempt to separate a highly purified target component is exceedingly difficult or would inevitably suffer a harsh decrement in yield after various treatments, due to the presence of lignincarbohydrate complexes (LCCs). In LCC structures, lignin is chemically bonded to a carbohydrate constituent; these connections are commonly via benzyl ethers, esters, and phenyl glycosides (Eriksson et al. 1980; Lundquist et al. 1983; Fengel and Wegener 1984). Some of these linkages are rather stubborn and severely interfere with the chemical and biochemical processing of lignocellulosics (Gierer and Wannstrom 1986; Iversen and Wannstrom 1986; Choi et al. 2007). Therefore, the significance and practicality of LCC fractionation could be briefly summarized into two aspects: i) beneficial for structural elucidation of possible lignin-carbohydrate (L-C) chemical linkages in given types of biomass materials, and thus providing theoretical guidance for efficient isolation of specific component; ii) direct utilization of LCCs as starting materials. Novel applications of LCCs have been investigated in recent years, and the isolated LCCs demonstrated pronounced capacities for radical scavenging and other pharmacological functions in terms of antitumor, antimicrobial, antiviral properties, etc. (Sakagami et al. 2005, 2010; Huang et al. 2018; Zhang et al. 2019; Dong et al. 2020).

In this study, to better understand the chemical relationships between lignin and carbohydrate components in coconut coir, it is the first time that various LCC fractions have been quantitatively isolated by building up an effective and simplified fractionation method according to previous research (Du et al. 2013, 2014). The structural information of the obtained LCCs have been further revealed by means of composition analysis, molecular weight distribution analysis, two dimensional heteronuclear singular quantum correlation (2D HSQC) NMR technique, etc. Moreover, the application potentials of various LCC products (known as natural polymers with lignin and polysaccharide bonded with each other) have been evaluated for their radical-scavenging abilities in the reference of a commercial antioxidant, as well as for their function as an adsorption-reinforcing agent in hydrogel preparation (first time) for sewage treatment. 


\section{EXPERIMENTAL}

\section{Materials and Reagents}

Waste coconut husk was collected from a local fruit store (Haikou, China). Dimethyl sulfoxide (DMSO), tetrabutylammonium hydroxide (TBAH, $40 \mathrm{wt} \%$ in water), 1-butyl-3-methylimidazolium chloride $([\mathrm{Bmim}] \mathrm{Cl})$, acrylamide $(\mathrm{AM}), \mathrm{N}, \mathrm{N}$-methylenebisacrylamide (MBA), and L-ascorbic acid were purchased from Macklin Biochemical Co., Ltd. (Shanghai, China). The 2,2-diphenyl-1-picryl-hydrazyl (DPPH) and 2,6-di-tertbutyl-4-methylphenol (BHT) were supplied by Shanghai Aladdin Biochemical Technology Co., Ltd. (Shanghai, China). Cellic CTec2 and Pentopan Mono BG, which served as cellulase and xylanase, were purchased from Sigma-Aldrich (St. Louis, MO, USA). The $30 \mathrm{wt} \%$ hydrogen peroxide solution and other chemicals of analytical reagent grade were provided by Guangzhou Chemical Reagent Co., Ltd. (Guangzhou, China) and were used as received.

\section{Methods}

Pretreatment of the raw material

Coconut coir was first separated from pre-cleaned coconut husk by mechanical disintegration. After Wiley-milling to pass through the size of 100 mesh and $24 \mathrm{~h}$ of Soxhlet extraction (benzene/ethanol, v/v $=2: 1$ ), the extractive-free meal further underwent $2 \mathrm{~h}$ (an interval of resting was set for $0.5 \mathrm{~h}$ after continuously working every $0.5 \mathrm{~h}$ ) of planetary ball milling (WXQM-0.4; Tencan Powder Technology Co., Ltd., Changsha, China) for preparation of a ball-milled sample that was kept in the desiccator for future use.

Screening of solvent system for ball-milled sample

Four different solvent systems were selected for dissolution of a $0.47 \mathrm{~g}$ coir ballmilled sample. All the treatment conditions are listed in Table 1. The dissolving efficiency of each solvent system was preliminarily evaluated by intuitive judgement, and then the feasibility for coir LCC fractionation was further verified by dilution of $2 \mathrm{~mL}$ of vigorously oscillated coir-solvent mixture with $20 \mathrm{~mL}$ deionized water.

Table 1. Treatment Conditions of Four Different Solvent Systems

\begin{tabular}{|c|c|c|c|}
\hline \multirow{2}{*}{ Sample } & Solvent Systems & $\begin{array}{c}\text { Treatment } \\
\text { Temp. } \\
\left({ }^{\circ} \mathrm{C}\right)\end{array}$ & $\begin{array}{c}\text { Treatment } \\
\text { Time } \\
(\mathrm{h})\end{array}$ \\
\hline \multirow{2}{*}{$\begin{array}{c}\text { Ball- } \\
\text { milled } \\
\text { powder } \\
(0.47 \mathrm{~g})\end{array}$} & $\mathrm{DMSO}(5 \mathrm{~mL})+\mathrm{TBAH}(5 \mathrm{~mL})$ & $\mathrm{RT}^{\mathrm{a}}$ & 12 \\
\cline { 2 - 4 } & $8 \% \mathrm{LiCl} / \mathrm{DMSO}(10 \mathrm{~mL})$ & $\mathrm{RT}$ & 12 \\
\cline { 2 - 4 } & {$[\mathrm{Bmim}] \mathrm{Cl}(10 \mathrm{~g})$} & 110 & 12 \\
\hline
\end{tabular}

a RT: room temperature

\section{Fractionation of coir LCCs}

As illustrated in Table 1 and Fig. 1, the $0.47 \mathrm{~g}$ ball-milled sample was evenly distributed and dissolved in a binary solvent system consisting of DMSO $(5 \mathrm{~mL})$ and TBAH $(5 \mathrm{~mL})$ under room temperature for $12 \mathrm{~h}$. After complete dissolution, the clear solution was diluted with $100 \mathrm{~mL}$ of deionized water, followed by the separation of the 
precipitate and supernatant. The first LCC fraction $(0.32 \mathrm{~g})$, designated as glucan-lignin (GL), was obtained from the precipitate after a thorough wash with deionized water and the subsequent lyophilization. The second LCC fraction $(0.12 \mathrm{~g})$, denoted as xylan-lignin (XL), was reclaimed from the supernatant by a series of purification steps including $\mathrm{pH}$ neutralization, dialysis, and lyophilization.

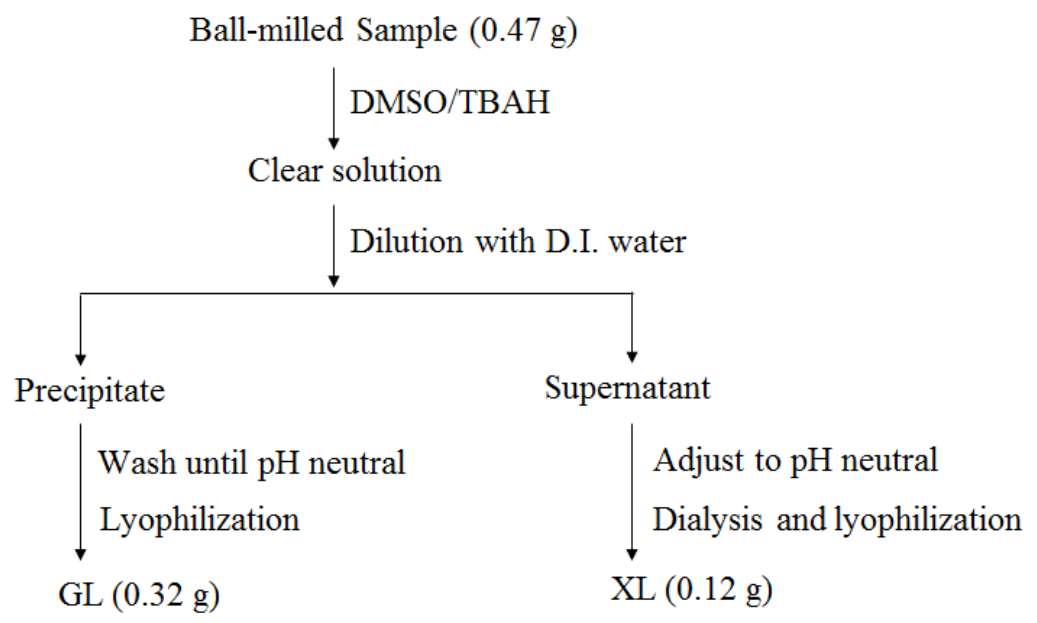

Fig. 1. The flow chart of coir LCC fractionation

\section{Chemical composition analysis}

The ash, extractives, Klason lignin and acid soluble lignin contents were determined following TAPPI standard methods TAPPI T211 om-07 (2007), TAPPI T204 cm-97 (1997), TAPPI T222 om-06 (2006), and TAPPI UM 250 (1985), respectively. The carbohydrate composition was analyzed according to the method described by Theander and Westerlund (1986).

\section{Structural characterization of LCCs}

The molecular weight distribution of the two LCC fractions were analyzed using a Waters 1515 gel permeation chromatography system (Wasters Corporation, Concord, MA, USA), employing two columns (Styragel HT 2 and Styragel HT 4) coupled in series. Some LCC samples were pre-acetylated to enhance their solubilities in the eluent of dimethylformamide. A Waters 2998 UV detector (Wasters Corporation, Concord, MA, USA) was equipped for detection at $280 \mathrm{~nm}$. The eluent flow rate was set as $1 \mathrm{~mL} / \mathrm{min}$, and polystyrene standards were applied with the molecular weight ranging from $1220 \mathrm{Da}$ to 326,000 Da. The crystallinity patterns of various samples including Wiley-milled coir, ball-milled coir, GL, and XL were investigated using a Rigaku MiniFlex 600 X-ray diffractometer (Rigaku Corporation, Osaka, Japan) equipped with a $\mathrm{Ni}$ filtered $\mathrm{CuK} \alpha$ radiation at $15 \mathrm{~mA}$ and $40 \mathrm{kV}$. All the measurements were performed from $10^{\circ}$ to $40^{\circ}$ with a scanning rate of $1 \% \mathrm{~min}$. The enzymatic hydrolysis of LCCs was performed prior to NMR analyses, and the process conditions were as follows: $200 \mathrm{mg}$ GL was incubated with $1 \mathrm{~mL}$ cellulase and $9 \mathrm{~mL}$ buffer solution (100 mM, HAc/NaAc, and $\mathrm{pH} 4.8)$ at $50{ }^{\circ} \mathrm{C}$ for $72 \mathrm{~h}$. The hydrolyzed residue (En-GL) was thoroughly rinsed with deionized water under vacuum filtration prior to lyophilization. The En-GL sample was further acetylated for 
enhancement of its solubility in NMR solvent. For XL, $100 \mathrm{mg}$ commercial xylanase powder was pre-dissolved in $10 \mathrm{~mL}$ buffer solution $(100 \mathrm{mM}, \mathrm{HAc} / \mathrm{NaAc}$, and $\mathrm{pH} 4.8)$ to free the xylanase from its original carrier. After centrifugation, the collected supernatant was mixed with $200 \mathrm{mg}$ of XL and was incubated at $50{ }^{\circ} \mathrm{C}$ for $72 \mathrm{~h}$. The enzymatically hydrolyzed XL residue (En-XL) was reclaimed after thorough washing and lyophilization. For NMR experiments, $600 \mu \mathrm{L} \mathrm{CDCl}_{3}$ or DMSO-d 6 was selected for dissolution of $30 \mathrm{mg}$ acetylated En-GL (Ac-En-GL) or En-XL, respectively. The 2D HSQC NMR spectra were recorded on a Bruker $500 \mathrm{MHz}$ spectrometer (Bruker BioSpin AG, Fällanden, Switzerland) using a standard Bruker pulse program at room temperature (Du et al. 2014).

\section{Assay of radical-scavenging ability}

The radical-scavenging abilities of LCCs were evaluated by removal of DPPH. The assay procedure was performed according to a previous method (Niu et al. 2016). Specific volumes of DPPH (0.1 mM in ethanol) were charged into LCC or BHT aqueous suspensions of different consistencies. The UV absorbance was recorded at $517 \mathrm{~nm}$ after 30 min of reaction, and all the measurements were performed in triplicate.

\section{Preparation of LCC-reinforced hydrogels}

A prescribed amount of LCC fraction was suspended into $3.5 \mathrm{~mL}$ of deionized water and then homogenized by using an ultrasonic cell crusher (JY98-IIIL; Derclaire Instrument Co. Ltd., Hangzhou, China). Next, $1.70 \mathrm{~g} \mathrm{AM}$ and $0.01 \mathrm{~g}$ MBA were charged and dissolved in the LCC aqueous suspension by magnetic stirring for $30 \mathrm{~min}$, prior to the addition of initiators consisting of $100 \mu \mathrm{L}$ hydrogen peroxide $(30 \mathrm{wt} \%)$ and $100 \mu \mathrm{L}$ ascorbic acid (6 $\mathrm{wt} \%)$. The resultant suspension was continued for $20 \mathrm{~min}$ of magnetic stirring under nitrogen gas atmosphere, and the LCC-reinforced hydrogels were polymerized in a sealed round glass container in a $70{ }^{\circ} \mathrm{C}$ air bath for $9 \mathrm{~h}$. The acquired products were soaked in deionized water for $48 \mathrm{~h}$ to remove the unreacted AM and other impurities. The impurity-free hydrogels were further lyophilized and kept for adsorption experiments without size reduction.

\section{Determination of adsorption property of LCC-reinforced hydrogels}

The adsorption properties of LCC-reinforced hydrogels were evaluated by adsorption of methylene blue. A sample of 0.1 g polyacrylamide (PAM) hydrogel or LCCreinforced polyacrylamide hydrogel was added to $20 \mathrm{~mL}$ of $20 \mathrm{mg} / \mathrm{L}$ methylene blue aqueous solution, and the adsorption of the solution was measured after $72 \mathrm{~h}$ ranging from $400 \mathrm{~nm}$ to $800 \mathrm{~nm}$.

\section{RESULTS AND DISCUSSION}

\section{Screening of the Complete-coir-dissolution System}

To realize the quantitative fractionation of coir LCCs, a sufficient dissolution system for the raw material is crucial. In this study, some previously reported or commonly adopted solvent systems (Kilpeläinen et al. 2007; Wang et al. 2009; Du et al. 2013; Chen et al. 2018) for lignocellulosics were selected (Table 1). After $12 \mathrm{~h}$ of dissolution time, $1 \#$, $3 \#$, and 4\# mixtures all turned out to be clear liquid by qualitative visual observation, while 
2\# mixture still remained in a cloudy state (Fig. 2a). It is to be noted that an effective solvent system formerly documented for certain feedstocks may not be applicable for other lignocellulosic species due to the variation of chemical compositions. Moreover, some classic lignocellulosic solvent systems are also sensitive to other factors, e.g., sample particle size, moisture, etc. (Kilpeläinen et al. 2007). In addition to the solubility, the applicability of each solvent system for coir LCC fractionation was further evaluated, and the fractionation efficiencies are demonstrated in Fig. 2b. As for 1\# system, a considerable portion of solutes had been effectively distributed into the supernatant with less amount of residue left as another type of fraction. The rest three systems all exhibited limited capacities in effectively fractionating different fractions, since majority of the solutes were precipitated as residues after anti-solvent (water) dilution. Taken together, the DMSO/ TBAH system was screened out for the subsequent fractionation of coir LCC fractions.

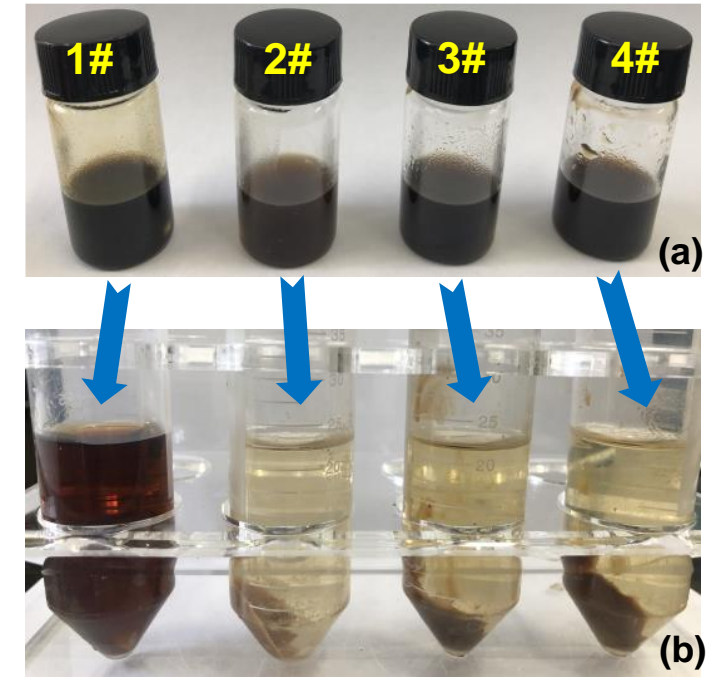

$12 \mathrm{~h}$ of dilution

After dilution \& centrifugation

Fig. 2. Dissolving (a) and LCC fractionation (b) efficiencies of "DMSO+TBAH" (1\#), 8\% LiCl/DMSO $(2 \#),[\mathrm{Bmim}] \mathrm{Cl}(3 \#)$, and "DMSO+[Bmim]Cl" (4\#) solvent systems

\section{Coir LCC Fractionation}

Besides polysaccharides, other chemical constituents in coir consist of extractives $(5.6 \%)$, lignin $(33.0 \%)$, and a low content of ash (0.9\%) (Table 2). Glucose and xylose were the two dominating monosaccharides detected after dilute acid hydrolysis, while other common monosaccharides (e.g., mannose, arabinose, and galactose) were undetectable. The contents of glucan $(38.6 \%)$ and xylan $(16.2 \%)$ in coir were calculated according to the amounts of glucose and xylose, respectively (Table 2). The deficiency of mannose simplifies the procedure of coir LCC fractionation by skipping an isolation step of glucomannan-lignin (widely present in softwood species), according to previous findings (Li et al. 2011a; Du et al. 2013). Therefore, the fractionation work was chiefly designed to focus on the separation of the GL fraction and the XL fraction (Fig. 1). After dilution of the coir-complete-dissolution system with deionized water, the fraction with higher molecular weight was precipitated out. Its chemical composition was composed of a rich amount of glucan $(50.4 \%)$ and a considerable quantity of lignin $(27.5 \%)$, and thus was designated as glucan-lignin (GL) (Fig. 1). The leftover fraction remaining in the supernatant solution, with relatively lower molecular weight, was denoted as XL (Fig. 1). 
XL was greatly enriched in lignin (39.5\%) and xylan (27.6\%) (Table 2). Notably, the fractionation of coir LCCs is quantitative because the yields of GL (68.1\%) and XL $(25.5 \%)$ are summed up to $93.6 \%$ of the starting raw material.

Table 2. Composition Analysis of Coir and Coir LCCs

\begin{tabular}{|c|c|c|c|c|c|c|c|}
\hline Samples & $\begin{array}{c}\text { Yield } \\
(\%)\end{array}$ & $\begin{array}{c}\text { Ash } \\
(\%)\end{array}$ & $\begin{array}{c}\text { Extractives } \\
(\%)\end{array}$ & $\begin{array}{c}\text { Klason } \\
\text { Lignin } \\
(\%)\end{array}$ & $\begin{array}{c}\text { Acid } \\
\text { Soluble } \\
\text { Lignin } \\
(\%)\end{array}$ & $\begin{array}{c}\text { Glucan } \\
(\%)\end{array}$ & $\begin{array}{c}\text { Xylan } \\
(\%)\end{array}$ \\
\hline Coir & 100 & $0.9 \pm 0.1$ & $5.6 \pm 0.5$ & $31.1 \pm 0.5$ & $1.9 \pm 0.1$ & $38.6 \pm 0.5$ & $16.2 \pm 0.3$ \\
\hline GL & $68.1 \pm 0.3$ & - & - & $25.9 \pm 0.9$ & $1.6 \pm 0.1$ & $50.4 \pm 0.8$ & $12.8 \pm 0.2$ \\
\hline $\mathrm{XL}$ & $25.5 \pm 0.6$ & - & - & $36.2 \pm 0.6$ & $3.3 \pm 0.1$ & $1.8 \pm 0.1$ & $27.6 \pm 0.5$ \\
\hline
\end{tabular}

\section{Structural Characterization of Coir LCCs}

Compared with Ac-XL $\left(\mathrm{M}_{\mathrm{w}}=1.15 \times 10^{4} \mathrm{Da}\right)$, Ac-GL has a much higher molecular weight $\left(M_{\mathrm{w}}=1.25 \times 10^{5} \mathrm{Da}\right)$, which is in good agreement with the fact that GL was the first fraction precipitated out from the diluted complete-coir-dissolution system. A narrower molecular weight distribution of GL can also be featured from the comparison of polydispersities of Ac-GL (1.62) and Ac-XL (2.21).

Table 3. Molecular Weight Distribution of Various LCC Samples

\begin{tabular}{|c|c|c|c|c|}
\hline Sample & $M_{w}$ & $M_{\mathrm{n}}$ & $M_{\mathrm{p}}$ & Polydispersity \\
\hline $\mathrm{Ac}_{\mathrm{GLL}}{ }^{\mathrm{a}}$ & $1.25 \times 10^{5}$ & $7.76 \times 10^{4}$ & $2.21 \times 10^{5}$ & 1.62 \\
\hline $\mathrm{Ac}-\mathrm{XL}^{\mathrm{b}}$ & $1.15 \times 10^{4}$ & $5.19 \times 10^{3}$ & $8.36 \times 10^{3}$ & 2.21 \\
\hline $\mathrm{XL}$ & $6.69 \times 10^{3}$ & $3.76 \times 10^{3}$ & $5.37 \times 10^{3}$ & 1.78 \\
\hline $\mathrm{Ac}-\mathrm{En}-\mathrm{GL}^{\mathrm{c}}$ & $1.67 \times 10^{4}$ & $5.38 \times 10^{3}$ & $7.68 \times 10^{3}$ & 3.11 \\
\hline $\mathrm{En}-\mathrm{XL}^{\mathrm{d}}$ & $5.77 \times 10^{3}$ & $3.54 \times 10^{3}$ & $4.98 \times 10^{3}$ & 1.63 \\
\hline
\end{tabular}

${ }^{a}$ Ac-GL: acetylated glucan-lignin;

${ }^{b}$ Ac-XL: acetylated xylan-lignin;

${ }^{c}$ Ac-En-GL: enzymatically hydrolyzed and acetylated glucan-lignin;

${ }^{d}$ En-XL: enzymatically hydrolyzed xylan-lignin

The X-ray diffraction (XRD) spectrum of Wiley-milled coir is demonstrated in Fig. 3 with characteristic peaks located at $2 \theta$ of $15.0^{\circ}$ (101 plane), $16.5^{\circ}$ (10i plane), and $22.5^{\circ}$ (002 plane). However, most of the original crystalline structures of cellulose present in coir had been severely interrupted during the process of ball milling, which favored the dissolution of ball-milled coir in the DMSO/THAH system. The remaining crystalline sections of cellulose in coir after ball milling experienced dissolution in the DMSO/THAH system and regenerated in deionized water successively, during which the original form of cellulose I was transformed to cellulose II, as reflected by the new diffraction peaks of GL in contrast to Wiley-milled coir (Henrique et al. 2015; Jin et al. 2016). It is reasonable that no obvious crystalline peaks were observed for the XRD pattern of XL, for the dominating structural constituents (xylan and lignin) in XL are more defined as amorphous structures. 


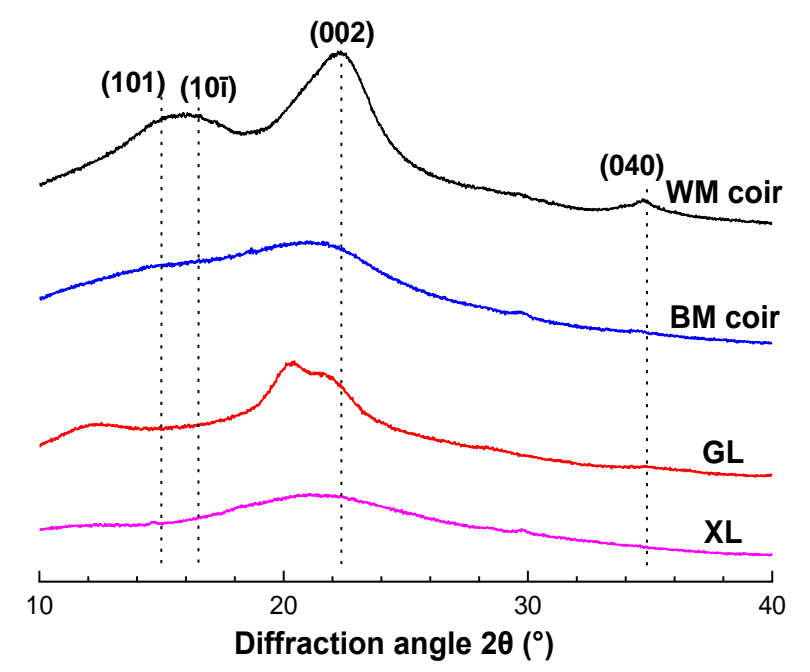

Fig. 3. X-ray diffraction spectra of Wiley-milled (WM) coir, ball-milled (BM) coir, glucan-lignin $(\mathrm{GL})$, and xylan-lignin (XL)

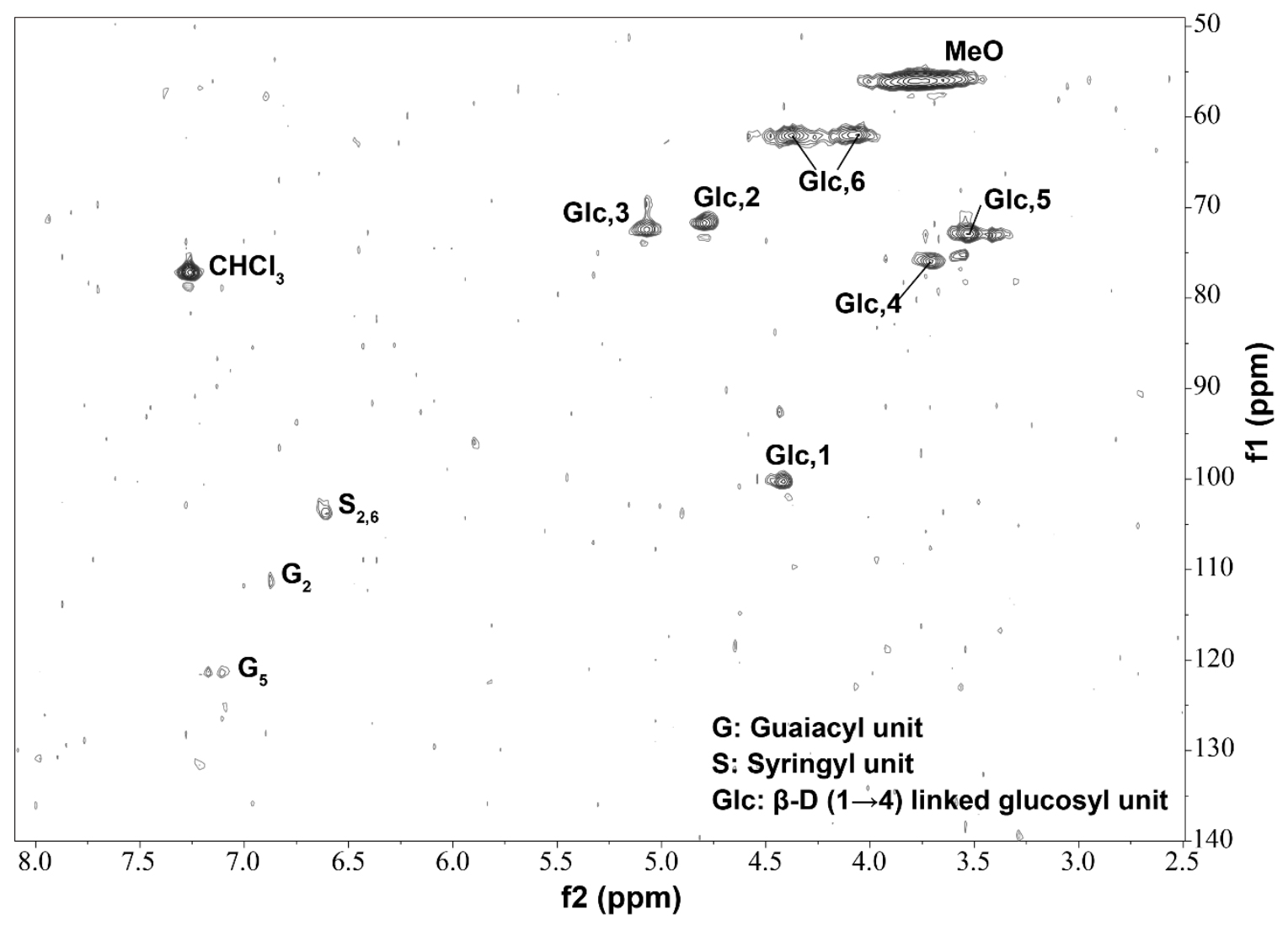

Fig. 4. 2D HSQC NMR spectrum of enzymatically hydrolyzed and acetylated glucan-lignin (AcEn-GL)

According to a previous study (Du et al. 2013), the NMR signals of LCCs with large molecular weight would be inevitably weakened or even undetectable due to fast spin-spin relaxation (Zhang and Gellerstedt 2007). Thus, the GL fraction was first treated 
with enzymatic hydrolysis to digest the glucan constituent in GL to a large extent. The efficient reduction of molecular weights of the two LCC fractions can be readily confirmed from the results of GPC (Table 3), e.g., $1.67 \times 10^{4} \mathrm{Da}\left(M_{\mathrm{w}}\right.$ of Ac-En-GL) vs. $1.25 \times 10^{5}$ $\mathrm{Da}\left(M_{\mathrm{w}}\right.$ of Ac-GL), and $5.77 \times 10^{3} \mathrm{Da}\left(M_{\mathrm{w}}\right.$ of En-XL) $v s .6 .69 \times 10^{3} \mathrm{Da}\left(M_{\mathrm{w}}\right.$ of XL). To guarantee decent solubilities in respective NMR solvents, Ac-En-GL and En-XL were selected for the following 2D HSQC NMR analyses. As demonstrated in Fig. 4, typical polysaccharide signals from Ac-En-GL are clearly observed. For instance, the ${ }^{13} \mathrm{C}-{ }^{1} \mathrm{H}$ correlation signals at $\delta \mathrm{c} / \delta_{\mathrm{H}} 100.3 / 4.42\left(\mathrm{C}_{1} / \mathrm{H}_{1}\right), 71.7 / 4.79\left(\mathrm{C}_{2} / \mathrm{H}_{2}\right), 72.4 / 5.07\left(\mathrm{C}_{3} / \mathrm{H}_{3}\right)$, $76.0 / 3.71\left(\mathrm{C}_{4} / \mathrm{H}_{4}\right), 72.9 / 3.53\left(\mathrm{C}_{5} / \mathrm{H}_{5}\right)$, and 62.0/(4.06; 4.38) $\left(\mathrm{C}_{6} / \mathrm{H}_{6}\right)$ are stemmed from $\beta-$ D- $(1 \rightarrow 4)$ linked glucosyl units of glucan. Aside from a prominent signal of methoxy group, generally the aromatic signals from lignin are fairly weak, but still can be identified as signals of $\mathrm{C}_{2,6}-\mathrm{H}_{2,6}$ correlations from syringal units and $\mathrm{C}_{2,5}-\mathrm{H}_{2,5}$ correlations from guaicyl units. The reason behind this was probably because the residual glucan present in Ac-EnGL still contains a highly crystalline structure, because enzymatic hydrolysis and the subsequent acetylation are preferential in digestion of the amorphous area of glucan and acetylation of the surface hydroxyl groups of glucan. Both operations mentioned above have less impact on interruption of the remaining crystalline regions of glucan in GL fraction.

However, the 2D HSQC spectrum of En-XL is more informative (Fig. 5), for its lower molecular weight and good solubility in DMSO- $d_{6}$. In addition to the typical cross signals from $\beta-\mathrm{D}-(1 \rightarrow 4)$ linked xylosyl units of xylan, located at $\delta_{\mathrm{C}} / \delta_{\mathrm{H}} 101.6 / 4.27\left(\mathrm{C}_{1} / \mathrm{H}_{1}\right)$, 72.5/3.04 $\left(\mathrm{C}_{2} / \mathrm{H}_{2}\right), 73.9 / 3.25\left(\mathrm{C}_{3} / \mathrm{H}_{3}\right), 75.3 / 3.50\left(\mathrm{C}_{4} / \mathrm{H}_{4}\right)$, and $63.1 /(3.17 ; 3.87)\left(\mathrm{C}_{5} / \mathrm{H}_{5}\right)$, a substantial amount of lignin cross signals have been detected from side chains and aromatic regions (Fig. 5). As revealed in the aromatic region of HSQC spectrum, signals from three different lignin units $(\mathrm{H}, \mathrm{G}$, and $\mathrm{S})$ are observed. For instance, the cross signal at $\delta_{\mathrm{C}} / \delta_{\mathrm{H}}$ 127.8/7.17 originates from the $\mathrm{C}_{2,6}-\mathrm{H}_{2,6}$ correlation in $\mathrm{H}$ units. The cross peaks at $\delta \mathrm{c} / \delta_{\mathrm{H}}$ 111.1/6.97 and 103.8/6.69 are two characteristic signals of $\mathrm{C}_{2}-\mathrm{H}_{2}$ and $\mathrm{C}_{2,6}-\mathrm{H}_{2,6}$ correlations from $\mathrm{G}$ and $\mathrm{S}$ units, respectively. The presence of $p$-hydroxybenzoate (PB) in coir is additionally verified. PB is reported as a common substructure in many plants, which is generated after acylation of $\gamma-\mathrm{OH}$ of the lignin side chain with $p$-hydroxybenzoic acid (Rencoret et al. 2013).

A cross signal belonging to the $\mathrm{C}_{2,6}-\mathrm{H}_{2,6}$ correlation of $\mathrm{PB}$ is observed at $\delta_{\mathrm{C}} / \delta_{\mathrm{H}}$ 131.3/7.65. The cross peaks of $\mathrm{C}_{3,5}-\mathrm{H}_{3,5}$ correlations from $\mathrm{PB}$ substructures and $\mathrm{H}$ units are overlapped together with the signals of $\mathrm{C}_{5,6}-\mathrm{H}_{5,6}$ correlations from $\mathrm{G}$ units. The relative abundances of different lignin units $(\mathrm{H}, \mathrm{G}$, and $\mathrm{S})$, as well as PB were semi-quantitatively estimated based on their respective $\mathrm{C}_{2}-\mathrm{H}_{2}$ correlation signals. The integration of a $\mathrm{G}_{2}$ cross signal was taken as an internal standard (Sette et al. 2013). The results are listed in Table 4. $\mathrm{G}$ units accounting for $51.3 \%$ out of all three lignin units are predominant in number and then followed by S units (44.4\%) and $\mathrm{H}$ units (4.3\%). The $\mathrm{S} / \mathrm{G}$ ratio was calculated as 0.87 , which is tremendously higher than 0.23 , as previously reported, when analyzing MWL from coconut coir (Rencoret et al. 2013). Therefore, it implies that $\mathrm{S}$ units are more prone to be chemically bonded with xylan in contrast to $\mathrm{G}$ units in coconut coir. The quantity of p-hydroxybenzoates was estimated as 10.9 per 100 lignin units, which is analogous to a previous study (Rencoret et al. 2013). 
Table 4. Relative Abundance/Quantity Ratios of Various Lignin Substructures

\begin{tabular}{|c|c|}
\hline Lignin Substructures & Relative Abundance/Quantity Ratio \\
\hline$\beta-O-4$ ' linkages & $90.0 \%$ \\
\hline Phenylcoumaran & $10.0 \%$ \\
\hline H units & $4.3 \%$ \\
\hline G units & $51.3 \%$ \\
\hline S units & $44.4 \%$ \\
\hline S/G ratio & 0.87 \\
\hline H/G ratio & 0.08 \\
\hline$p-$ Hydroxybenzoates & 10.9 per 100 lignin units \\
\hline$\gamma$-Esters & 3.6 per 100 lignin units \\
\hline Benzyl ethers & N.D. \\
\hline Phenyl glycosides & N.D. \\
\hline
\end{tabular}

N.D.- not determined

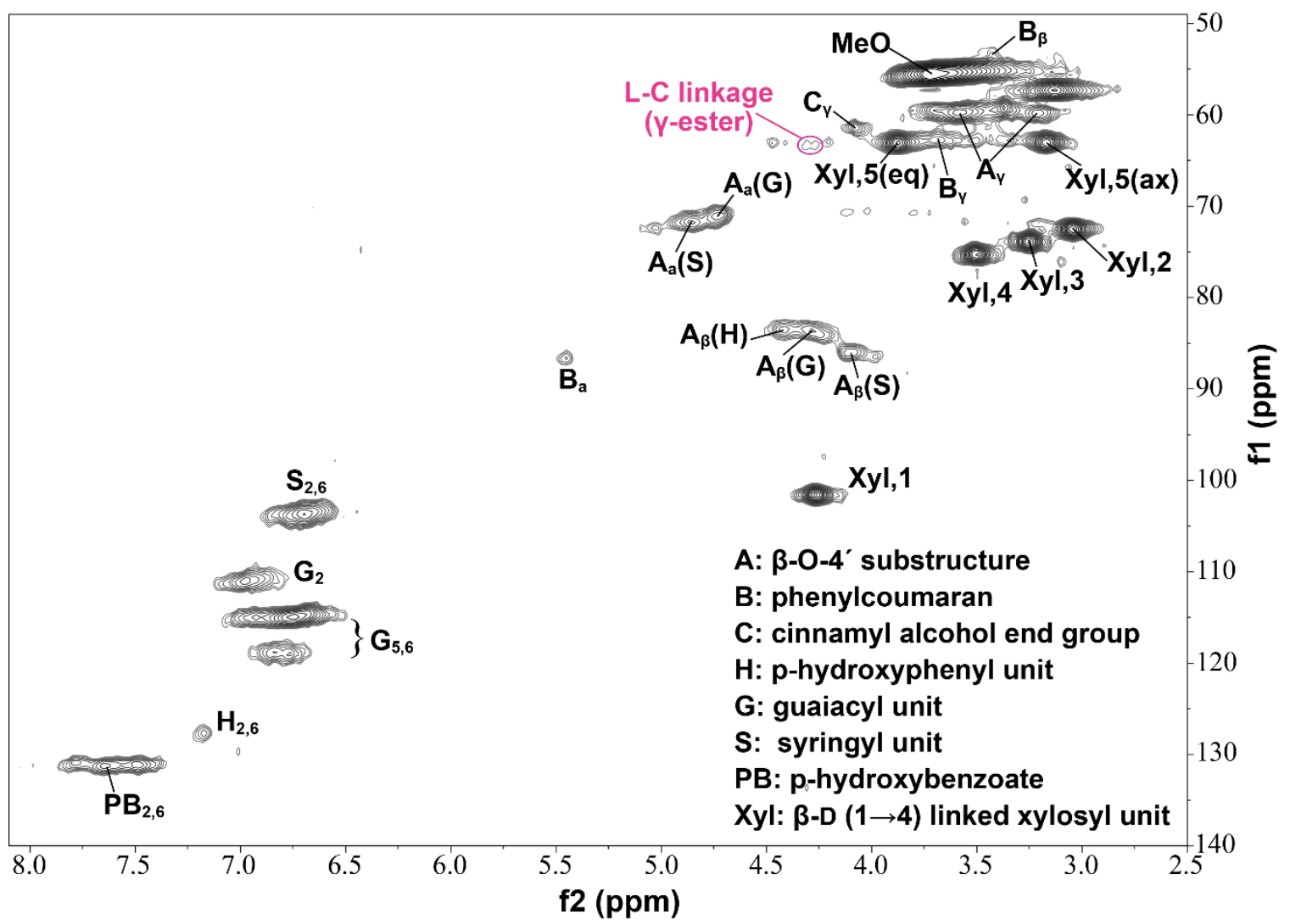

Fig. 5. 2D HSQC NMR spectrum of enzymatically hydrolyzed xylan-lignin (En-XL)

More structural information regarding the side chains of different lignin substructures are shown by the region of $\delta_{\mathrm{C}} / \delta_{\mathrm{H}} 50$ to $90 / 2.5$ to 6.0. Two sets of cross peaks are clearly assignable from alkyl ether linkages $\left(\beta-\mathrm{O}-4^{\prime}\right)$ and phenylcoumaran $\left(\beta-5^{\prime}\right)$ substructures. For instance, the $\mathrm{C}_{\alpha}-\mathrm{H}_{\alpha}$ correlations of $\beta-\mathrm{O}-4$ ' linkages and their $\gamma-$ acetylated counterparts are observed at $\delta_{\mathrm{C}} / \delta_{\mathrm{H}} 71.1 / 4.74$ (G units), and 71.8/4.86 (S units). 
Likewise, the $\mathrm{C}_{\beta}-\mathrm{H}_{\beta}$ correlations of $\beta-\mathrm{O}-4$ ' linkages are detected at $\delta_{\mathrm{C}} / \delta_{\mathrm{H}} 83.5 / 4.42(\mathrm{H}$ units), 83.6/4.28 ( $\mathrm{G}$ units), and 86.0/4.10 ( $\mathrm{S}$ units). The signals of $\mathrm{C}_{\gamma}-\mathrm{H}_{\gamma}$ correlations from $\beta-\mathrm{O}-4$ ' linkages are overlapped at $\delta \mathrm{C} / \delta_{\mathrm{H}} 59.8 /(3.22 ; 3.58)$. Compared with the prominent signals from $\beta-\mathrm{O}-4$ ' linkages, the correlation signals from phenylcoumaran substructures are relatively weak, but are readily observed at $\delta_{\mathrm{C}} / \delta_{\mathrm{H}} 86.6 / 5.45\left(\mathrm{C}_{\alpha}-\mathrm{H}_{\alpha}\right.$ correlation), 53.5/3.41 ( $\mathrm{C}_{\beta}-\mathrm{H}_{\beta}$ correlation), and 62.8/3.67 ( $\mathrm{C}_{\gamma}-\mathrm{H}_{\gamma}$ correlation). The relative abundance of $\beta-\mathrm{O}-4$ ' linkages is $90 \%$ with the other $10 \%$ reserved for phenylcoumaran, based on the total integration of $\mathrm{C}_{\alpha}-\mathrm{H}_{\alpha}$ correlation signals of these two interunit linkages. Thus, the lignin present in XL is more linear and less condensed as deduced by a higher content of $\beta-\mathrm{O}-4$ ' linkages.

According to the authors' previous study (Du et al. 2014), hemicellulose (e.g., glucomannan and xylan) rather than glucan plays a larger role in formation of lignincarbohydrate (L-C) chemical bonds. In this study, xylan (the dominating hemicellulose in coir) is proposed to chemically link to lignin via the formation of ester of 4-Omethylglucuronic acid on lignin at the $\mathrm{C}_{\gamma}$ position ( $\gamma$-ester linkages), whose NMR signal is observed in Fig. 5. Its relative abundance is further estimated as 7 per $100 \mathrm{G}$ units (or 3.6 per 100 lignin units). The other two common L-C chemical linkages (namely benzyl ethers and phenyl glycosides) are however not detected.

\section{Radical-scavenging Abilities of Coir LCCs}

The radical-scavenging abilities of coir LCCs were evaluated in contrast with a commercial antioxidant known as BHT. Generally, higher efficiency of radical-scavenging was achieved with the increment of sample consistency. Under the same sample consistency, the radical-scavenging ability of XL was superior to that of GL (Fig. 6). For instance, to reach half-inhibitory concentration ( $\left.\mathrm{IC}_{50}\right)$ of $\mathrm{DPPH}$, the consistency of GL suspension should be more than $0.4 \mathrm{mg} / \mathrm{mL}$, while this value could be less than $0.2 \mathrm{mg} / \mathrm{mL}$ if XL suspension were applied.

The superiority of XL over GL in DPPH scavenging is observed throughout the whole sample concentration range (from 0 to $1.0 \mathrm{mg} / \mathrm{mL}$ ). It is noteworthy that the DPPHscavenging ability of XL was competitive when compared with BHT. Although BHT demonstrated potent scavenging ability of DPPH when sample concentration was lower than $0.2 \mathrm{mg} / \mathrm{mL}$, ascribed to its low molecular weight and high molecular activity, its superiority gradually reached a plateau and was taken over by XL when sample concentration exceeded $0.5 \mathrm{mg} / \mathrm{mL}$ (Fig. 6).

The lignin accounting for $39.5 \%$ in XL to a large extent remains many phenolic hydroxyls (key structures in scavenging DPPH) compared with its native status in coir, because no harsh treatment conditions were applied during coir LCC fractionation. Moreover, xylan was also reported to possess radical-scavenging ability especially in a conjugate form with other polymeric materials (e.g., chitosan) (Li et al. 2011b). According to the discussion above, XL can be served as a potent antioxidant not only for its excellent radical-scavenging ability, but also for its uncomplicated preparation procedure, low toxicity, and biocompatibility as a natural polymeric material. 


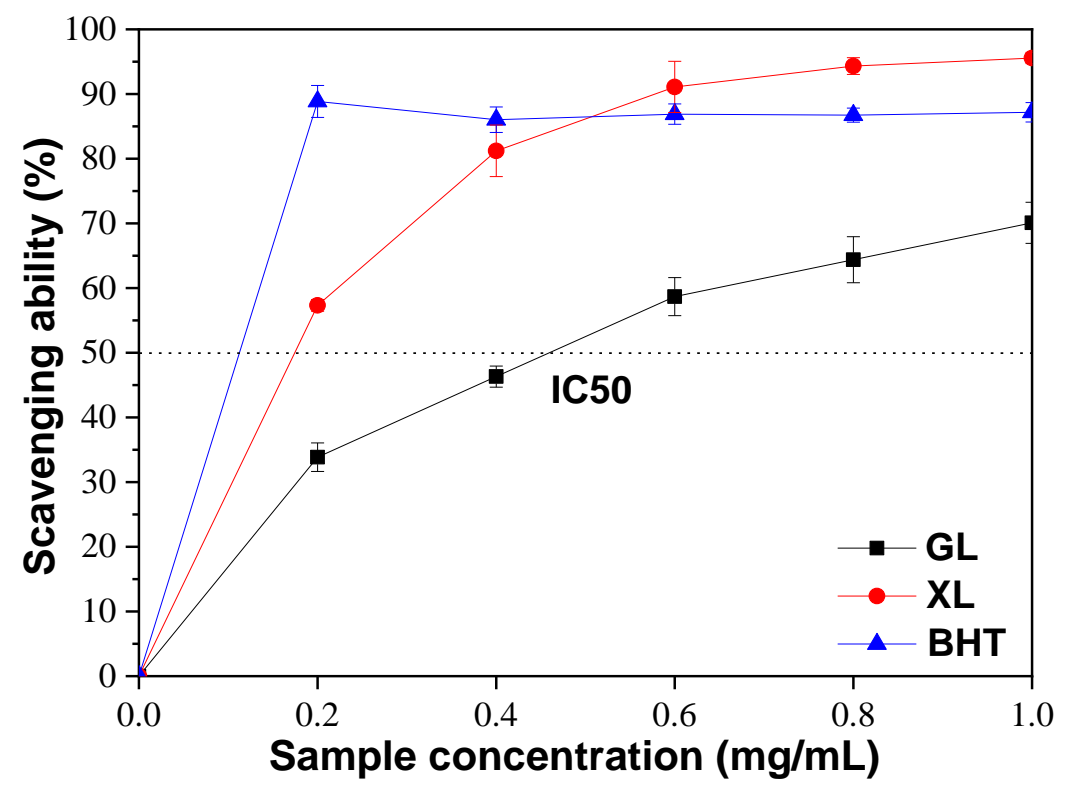

Fig. 6. DPPH scavenging abilities of 2, 2-diphenyl-1-picryl-hydrazyl (BHT), glucan-lignin (GL), and xylan-lignin $(\mathrm{XL})$

\section{Adsorption Property of LCC-reinforced Hydrogels}

In contrast to traditional PAM hydrogel, the adsorption capacity of LCC-reinforced PAM on methylene blue (MB) after $72 \mathrm{~h}$ was enhanced (Fig. 7a). The lower absorbance of the treated solution is in good conformity with the higher adsorption ability of the hydrogel sample applied. XL-reinforced PAM (XL-PAM) was more effective in MB removal than GL-reinforced PAM (GL-PAM). Proper reasons can be interpretted as follows: i) XL has higher dispersity and uniformity within the matrix of the final hydrogel product, due to its lower molecular weight, which favors the inter-molecular interactions beteen XL and MB, compared with the partically aggregated GL reinforcer; ii) the preponderance of lignin content in XL (39.5\% vs. $27.5 \%$ in GL) further faciliates the intermolecular physical adsoroption functioned by aromatic structures from both lignin and MB molecules. The possible interactions between LCC and MB molecules are proposed in Fig. 8.

In the early stage of adsorption $(<30 \mathrm{~min})$, the removal rate of $\mathrm{MB}$ rapidly and linearly increased with the prolongation of adsorption time (Fig. 7b). This phenomenon was caused by two factors: i) adequate adsorption sites are available on the surface of hydrogel products; ii) an evident driving force is formed for MB to transfer from the solution (high concentration) to the surface of hydrogels (low concentration). After $30 \mathrm{~min}$, many adsorption sites from the surface were occupied, and the further adsorption was largely achieved by the adsorption sites from the internal pores of the hydrogels. The continuously diminished MB concentration in solution, as well as the reduction of free adsorption sites, led to the adsorption equilibrium for all three hydrogel samples. 

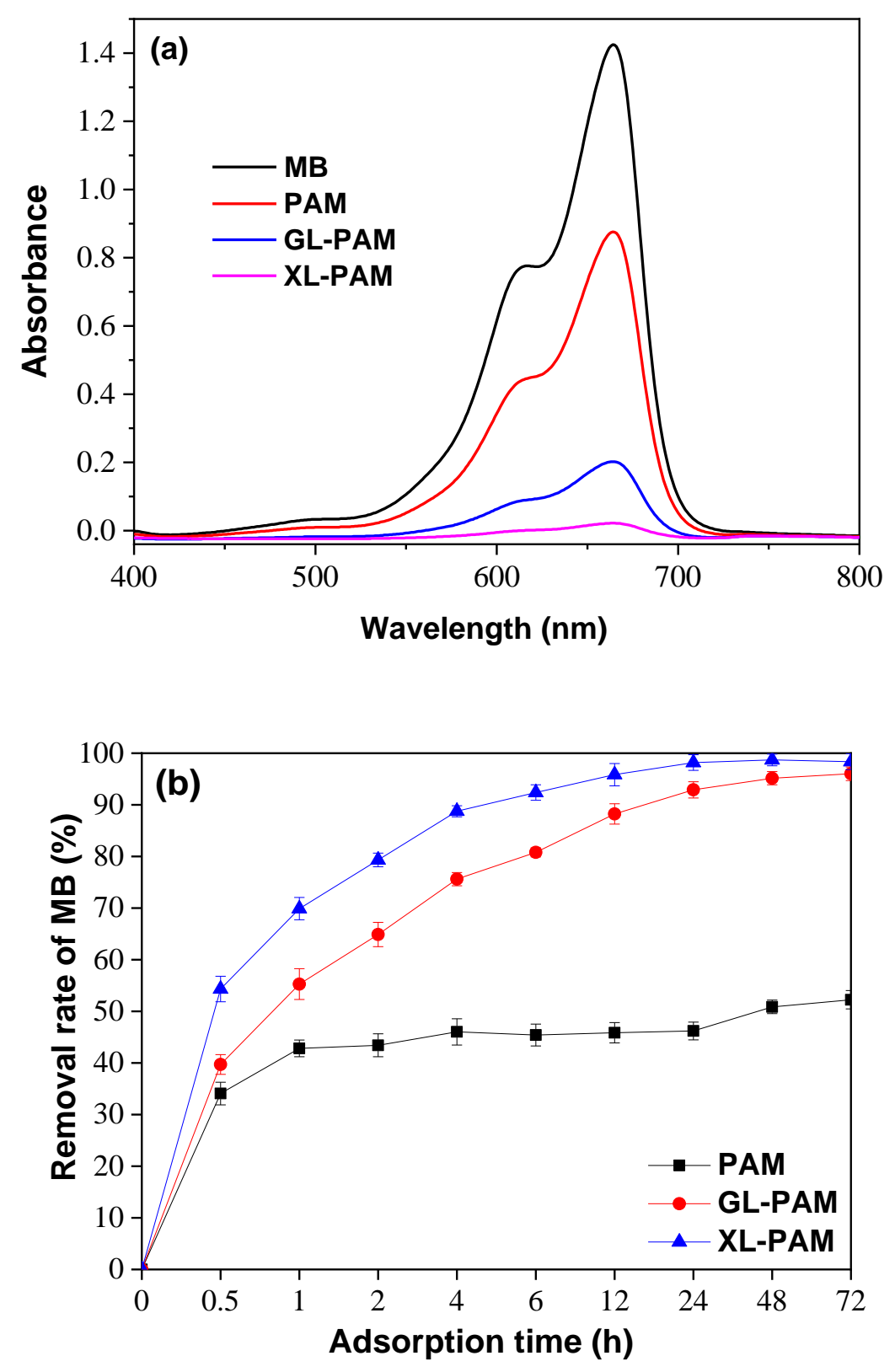

Fig. 7. Adsorption efficiencies (a) and removal capacities (b) of polyacrylamide (PAM), glucanlignin-reinforced polyacrylamide (GL-PAM), and xylan-lignin-reinforced polyacrylamide (XL-PAM) on methylene blue (MB)

It was noteworthy that two LCC-reinforced PAMs were more efficient in MB removal throughout the entire adsorption process, compared with pure PAM. For instance, the MB removal rates of XL-PAM and GL-PAM after $24 \mathrm{~h}$ were $98.2 \%$ and $92.9 \%$, respectively, but the same criteria for PAM $(24 \mathrm{~h})$ was less than $50 \%$. Abundant aromatic structures and hydroxyl groups from LCC macromolecules play a great role in enhancing the capacity of MB removal via physical and hydrogen bonding adsorptions. Therefore, 
natural polymeric LCCs, especially XL, can be applied as a highly promising adsorptionreinforcing agent for biodegradable materials.

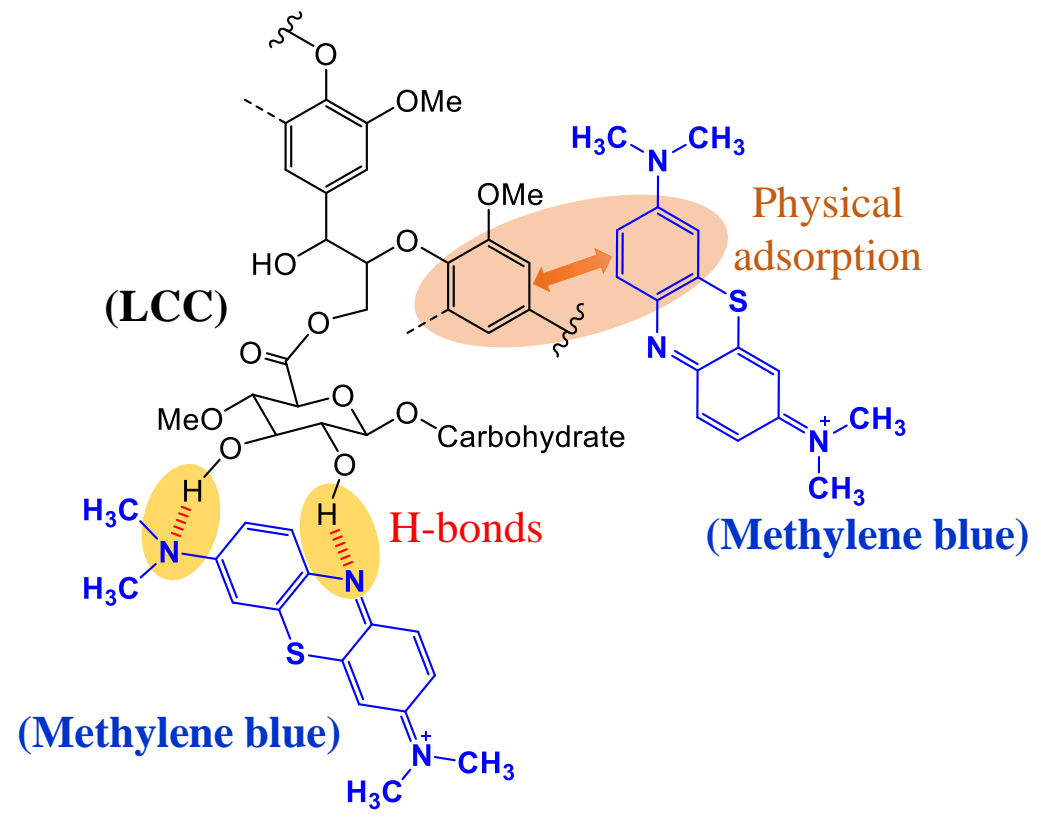

Fig. 8. Possible intermolecular interactions between LCC and MB molecules

\section{CONCLUSIONS}

1. Coconut coir isolated from waste coconut husk was quantitatively isolated into two lignin-carbohydrate complex (LCC) fractions designated as GL and XL.

2. Lignin syringyl units are more prone to chemically bond with xylan in contrast to guaiacyl units, and $\gamma$-esters have been revealed as the primary chemical linkages between lignin and xylan subunits by 2D HSQC NMR technique.

3. Due to rich lignin content and decent dispersity in aqueous solution, XL exhibits superior capacities in DPPH removal and elevation of adsorption property for polyacrylamide-based hydrogels, and thus can be further developed as an efficient and environment-friendly radical scavenger and/or an adsorption-reinforcing agent for biobased materials.

\section{ACKNOWLEDGEMENTS}

This study was financially supported by the Hainan Provincial Natural Science Foundation (318MS012, 2019RC154) and the start-up fund from Hainan University (KYQD(ZR)1717). 


\section{REFERENCES CITED}

Bian, H., Luo, J., Wang, R., Zhou, X., Ni, S., Shi, R., Fang, G., and Dai, H. (2019a). "Recyclable and reusable maleic acid for efficient production of cellulose nanofibrils with stable performance," ACS Sustainable Chemistry \& Engineering 7(24), 2002220031. DOI: 10.1021/acssuschemeng.9b05766

Bian, H., Zhou, X., Dong, M., Chen, L., Ni, S., Fang, G., and Dai, H. (2019b). "Comparison of mixed enzymatic pretreatment and post-treatment for enhancing the cellulose nanofibrillation efficiency," Bioresource Technology 293, 1-5. DOI: 10.1016/j.biortech.2019.122171

Bourdeix, R., and Prades, A. (2018). A Global Strategy for the Conservation and Use of Coconut Genetic Resources 2018-2028, Bioversity International.

Chen, X., Chen, X., Cai, X.-M., Huang, S., and Wang, F. (2018). "Cellulose dissolution in a mixed solvent of tetra(n-butyl)ammonium hydroxide/dimethyl sulfoxide via radical reactions," ACS Sustainable Chemistry \& Engineering 6(3), 2898-2904. DOI: 10.1021/acssuschemeng.7b04491

Cho, E. J., Trinh, L. T. P., Song, Y., Lee, Y. G., and Bae, H.-J. (2020). "Bioconversion of biomass waste into high value chemicals," Bioresource Technology 298, 1-12. DOI: 10.1016/j.biortech.2019.122386

Choi, J. W., Choi, D.-H., and Faix, O. (2007). "Characterization of lignin-carbohydrate linkages in the residual lignins isolated from chemical pulps of spruce (Picea abies) and beech wood (Fagus sylvatica)," Journal of Wood Science 53, 309-313. DOI: 10.1007/s10086-006-0860-x

Dong, H., Zheng, L., Yu, P., Jiang, Q., Wu, Y., Huang, C., and Yin, B. (2020). "Characterization and application of lignin-carbohydrate complexes from lignocellulosic materials as antioxidants for scavenging in vitro and in vivo reactive oxygen species," ACS Sustainable Chemistry \& Engineering 8(1), 256-266. DOI: 10.1021 /acssuschemeng. $9 \mathrm{~b} 05290$

Du, X., Gellerstedt, G., and Li, J. (2013). "Universal fractionation of lignin-carbohydrate complexes (LCCs) from lignocellulosic biomass: An example using spruce wood," The Plant Journal 74(2), 328-338. DOI: 10.1111/tpj.12124

Du, X., Pérez-Boada, M., Fernández, C., Rencoret, J., Del Río, J. C., Jiménez-Barbero, J., Li, J., Gutiérrez, A., and Martínez, A. T. (2014). "Analysis of lignin-carbohydrate and lignin-lignin linkages after hydrolase treatment of xylan-lignin, glucomannan-lignin and glucan-lignin complexes from spruce wood," Planta 239, 1079-1090. DOI: $10.1007 / \mathrm{s} 00425-014-2037-\mathrm{y}$

Eriksson, Ö.,Goring, D. A. I., and Lindgren B. O. (1980). "Structural studies on the chemical bonds between lignins and carbohydrates in spruce wood," Wood Science and Technology 14, 267-279. DOI: 10.1007/BF00383454

Fengel, D., and Wegener, G. (1989). Wood: Chemistry, Ultrastructure, Reactions, Walter de Gruyter, Berlin, Germany.

Gierer, J., and Wännström, S. (1986). "Formation of ether bonds between lignins and carbohydrates during alkaline pulping processes," Holzforschung 40(6), 347-352. DOI: $10.1515 / \mathrm{hfsg} .1986 .40 .6 .347$ 
Grishkewich, N., Mohammed, N., Tang, J., and, Tam, K. C. (2017). "Recent advances in the application of cellulose nanocrystals," Current Opinion in Colloid \& Interface Science 29, 32-45. DOI: 10.1016/j.cocis.2017.01.005

Henrique, M. A., Flauzino Neto, W. P., Silvério, H. A., Martins, D. F., Gurgel, L. V. A., Da Silva Barud, H., De Morais, L. C., and Pasquini, D. (2015). "Kinetic study of the thermal decomposition of cellulose nanocrystals with different polymorphs, cellulose I and II, extracted from different sources and using different types of acids," Industrial Crops and Products 76, 128-140. DOI: 10.1016/j.indcrop.2015.06.048

Huang, C., Tang, S., Zhang, W., Tao, Y., Lai, C., Li, X., and Yong, Q. (2018). "Unveiling the structural properties of lignin-carbohydrate complexes in bamboo residues and its functionality as antioxidants and immunostimulants," ACS Sustainable Chemistry \& Engineering 6(9), 12522-12531. DOI: 10.1021/acssuschemeng.8b03262

Huang, C., Wang, X., Liang, C., Jiang, X., Yang, G., Xu, J., and Yong, Q. (2019). "A sustainable process for procuring biologically active fractions of high-purity xylooligosaccharides and water-soluble lignin from Moso bamboo prehydrolyzate," Biotechnology for Biofuels 12(189), 1-13. DOI: 10.1186/s13068-019-1527-3

Iversen, T., and Wännström, S. (1986). "Lignin-carbohydrate bonds in a residual lignin isolated from pine kraft pulp," Holzforschung 40(1), 19-22. DOI: 10.1515/hfsg. 1986.40.1.19

Jin, E., Guo, J., Yang, F., Zhu, Y., Song, J., Jin, Y., and Rojas, O. J. (2016). "On the polymorphic and morphological changes of cellulose nanocrystals (CNC-I) upon mercerization and conversion to CNC-II," Carbohydrate Polymers 143, 327-335. DOI: 10.1016/j.carbpol.2016.01.048

Kilpeläinen, I., Xie, H., King, A., Granstrom, M., Heikkinen, S., and Argyropoulos, D. S. (2007). "Dissolution of wood in ionic liquids," Journal of Agricultural and Food Chemistry 55(22), 9142-9148. DOI: 10.1021/jf071692e

Li, J., Martin-Sampedro, R., Pedrazzi, C., and Gellerstedt, G. (2011a). "Fractionation and characterization of lignin-carbohydrate complexes (LCCs) from eucalyptus fibers," Holzforschung 65(1), 43-50. DOI: 10.1515/hf.2011.013

Li, X., Shi, X., Wang, M., and Du, Y. (2011b). "Xylan chitosan conjugate - A potential food preservative," Food Chemistry 126(2), 520-525. DOI:

10.1016/j.foodchem.2010.11.037

Lundquist, K., Simonson, R., and Tingsvik, K. (1983). "Lignin carbohydrate linkages in milled wood lignin preparations from spruce wood," Svensk Papperstidning 86(6), 44-47.

Menon, V., and Rao, M. (2012). "Trends in bioconversion of lignocellulose: Biofuels, platform chemicals \& biorefinery concept," Progress in Energy and Combustion Science 38(4), 522-550. DOI: 10.1016/j.pecs.2012.02.002

Naidu, D. S., Hlangothi, S. P., and John, M. J. (2018). "Bio-based products from xylan: A review," Carbohydrate Polymers 179, 28-41. DOI: 10.1016/j.carbpol.2017.09.064

Nascimento, D. M., Almeida, J. S., Dias, A. F., Figueiredo, M. C. B., Morais, J. P. S., Feitosa, J. P. A., and Rosa, M. F. (2014). "A novel green approach for the preparation of cellulose nanowhiskers from white coir," Carbohydrate Polymers 110, 456-463. DOI: 10.1016/j.carbpol.2014.04.053 
Niu, H., Song, D., Mu, H., Zhang, W., Sun, F., and Duan, J. (2016). "Investigation of three lignin complexes with antioxidant and immunological capacities from Inonotus obliquus," International Journal of Biological Macromolecules 86, 587-593. DOI: 10.1016/j.ijbiomac.2016.01.111

Pang, L., Gao, Z., Feng, H., Wang, S., and Wang, Q. (2019). "Cellulose based materials for controlled release formulations of agrochemicals: A review of modifications and applications," Journal of Controlled Release 316(28), 105-115. DOI: 10.1016/j.jconrel.2019.11.004

Ragauskas, A. J., Beckham, G. T., Biddy, M. J., Chandra, R., Chen, F., Davis, M. F., Davison, B. H., Dixon, R. A., Gilna, P., Keller, M., et al. (2014). "Lignin valorization: Improving lignin processing in the biorefinery," Science 344(6185), Article ID 1246843. DOI: 10.1126/science.1246843

Rencoret, J., Ralph, J., Marques, G., Gutiérrez, A., Martínez, A. T., and Del Río, J. C. (2013). "Structural characterization of lignin isolated from coconut (Cocos nucifera) coir fibers," Journal of Agricultural and Food Chemistry 61(10), 2434-2445. DOI: 10.1021/jf304686x

Sakagami, H., Hashimoto, K., Suzuki, F., Ogiwara, T., Satoh, K., Ito, H., Hatano, T., Takashi, Y., and Fujisawa, S. I. (2005). "Molecular requirements of lignincarbohydrate complexes for expression of unique biological activities," Phytochemistry 66(17), 2108-2120. DOI: 10.1016/j.phytochem.2005.05.013

Sakagami, H., Kushida, T., Oizumi, T., Nakashima, H., and Makino, T. (2010). "Distribution of lignin-carbohydrate complex in plant kingdom and its functionality as alternative medicine," Pharmacology \& Therapeutics 128(1), 91-105. DOI: 10.1016/j.pharmthera.2010.05.004

Sette, M., Lange, H., and Crestini, C. (2013). "Quantitative HSQC analyses of lignin: A practical comparison," Computational and Structural Biotechnology Journal 6(7), 17. DOI: $10.5936 /$ csbj.201303016

Srivaro, S., Tomad, J., Shi, J., and Cai, J. (2020). "Characterization of coconut (Cocos nucifera) trunk's properties and evaluation of its suitability to be used as raw material for cross laminated timber production," Construction and Building Materials 254, 119291. DOI: 10.1016/j.conbuildmat.2020.119291

TAPPI T204 cm-97 (1997). "Solvent extractives of wood and pulp," TAPPI Press, Atlanta, GA, USA.

TAPPI T211 om-07 (2007). "Ash in wood, pulp, paper and paperboard: Combustion at $525^{\circ} \mathrm{C}$," TAPPI Press, Atlanta, GA, USA.

TAPPI T222 om-06 (2006). "Acid-Insoluble lignin in wood and pulp," TAPPI Press, Atlanta, GA, USA.

TAPPI UM 250 (1985). "Acid soluble lignin in wood and pulps," TAPPI Press, Atlanta, GA, USA.

Theander, O., and Westerlund, E. A. (1986). "Studies on dietary fiber. 3. Improved procedures for analysis of dietary fiber," Journal of Agricultural and Food Chemistry 34(2), 330-336. DOI: 10.1021/jf00068a045

Wang, Z., Yokoyama, T., Chang, H.-M., and Matsumoto, Y. (2009). "Dissolution of beech and spruce milled woods in LiCl/DMSO," Journal of Agricultural and Food Chemistry 57(14), 6167-6170. DOI: 10.1021/jf900441q 
Wu, J., Du, X., Yin, Z., Xu, S., Xu, S. X., and Zhang, Y. (2019). "Preparation and characterization of cellulose nanofibrils from coconut coir fibers and their reinforcements in biodegradeable composite films," Carbohydrate Polymers 211, 4956. DOI: 10.1016/j.carbpol.2019.01.093

Zhang, L., and Gellerstedt, G. (2007). "Quantitative 2D HSQC NMR determination of polymer structures by selecting suitable internal standard references," Magnetic Resonance in Chemistry 45(1), 37-45. DOI: 10.1002/mrc.1914

Zhang, Y., Wang, S., Xu, W., Cheng, F., Pranovich, A., Smeds, A., Willför, S., and Xu, C. (2019). "Valorization of lignin-carbohydrate complexes from hydrolysates of Norway spruce: Efficient separation, structural characterization, and antioxidant activity," ACS Sustainable Chemistry \& Engineering 7, 1447-1456. DOI: 10.1021/acssuschemeng.8b05142

Article submitted: May 22, 2020; Peer review completed: July 12, 2020; Revised version received and accepted: July 25, 2020; Published: July 29, 2020.

DOI: 10.15376/biores.15.3.7100-7117 